\title{
FASCIOLA HEPATICA CASE WITH HEMOBILIA
}

\section{Ibrahim Halil Bahcecioglu, Hüseyin Ataseven, Erhan Aygen, Serdar Coskun, Nalan Kuzu, Fulya Ilhan}

Firat University, Faculty of Medicine, Elazig, Turkey: Division of Gastroenterology, Department of General Surgery, Internal Medicine and Immunology

Summary: Fasciola hepatica $(\mathrm{FH})$ can lead to important hepatobiliary diseases. Here we present a case of hemobilia associated with biliary FH, which is quite a rare case. The 41-year-old patient, who underwent common bile duct exploration due to hemobilia, was found to have arterial bleeding associated with ulcer caused by a dead parasite in the common bile duct. Hemobilia is a very rare complication associated with FH. When searching for the cause of hemobilia, FH should be considered.

Key words: Hemobilia; Fasciolosis; Hepatobiliary system

\section{Introduction}

Fasciola hepatica $(\mathrm{FH})$ is a parasite of the flatworm family of which snails are the intermediate hosts and which are seen commonly in domestic animals like sheep, goat and cattle, and sporadically in humans $(8,9,13)$. It is estimated that there are 2.4 million individuals infected with fasciolosis and a 180 million others at risk of infection in the world. Although fasciolosis is frequently seen in developing countries, there has been an increase in the number of cases reported from developed countries in the last decade. This zoonotic infection is commonly observed in Africa, Western Europe and Latin America (13). A study from Eastern Turkey (Elazig) recently reported a $2.78 \%$ seroprevalence (11).

In its chronic period it proceeds with cholecystitis, cholangitis, abscesses in the liver, icterus caused by obstruction and biliary colics $(2,14)$. Pancreatitis (16) and hemobilia (17) are fairly rare complications. Here we present a highly rare case of hemobilia associated with biliary $\mathrm{FH}$.

\section{Case report}

A 41-year-old male case presented at our hospital complaining of epigastric pain. The characteristics of pain were that it appeared in the epigastrium after meals and extended towards the back. His history included alcohol use. A physical examination revealed epigastric sensitivity. Laboratory findings showed that the whole blood count was in the normal range and there was no eosinophilia.

Ultrasound (US): The liver and pancreas were evaluated normal. His upper gastrointestinal (GIS) endoscopy showed gastritis. Computer tomography (CT): Liver parenchyma and pancreas were normal. The image in the common bile duct (CBD) was consistent with parasitosis, upon which endo- scopic retrograde cholangiography (ERCP) was performed. ERCP showed that the CBD lumen was about $1 \mathrm{~cm}$ in diameter and dilated. There was an irregular filling defect in the CBD. Sphincterotomy was conducted, and 3 broken down, flat, dead FH parasites were extracted from the CBD by a stone extraction balloon. After the procedure, the patient's complaints were seen to abate. Triclobendazole treatment was started. One week after ERCP the patient presented with bleeding in the upper GIS. The upper GIS endoscopy showed that the bleeding originated from the CBD. A second ERCP was performed on the patient. The CBD was minimally dilated. There was a heterogeneous irregular filling defect at the lower end. Intrahepatics were

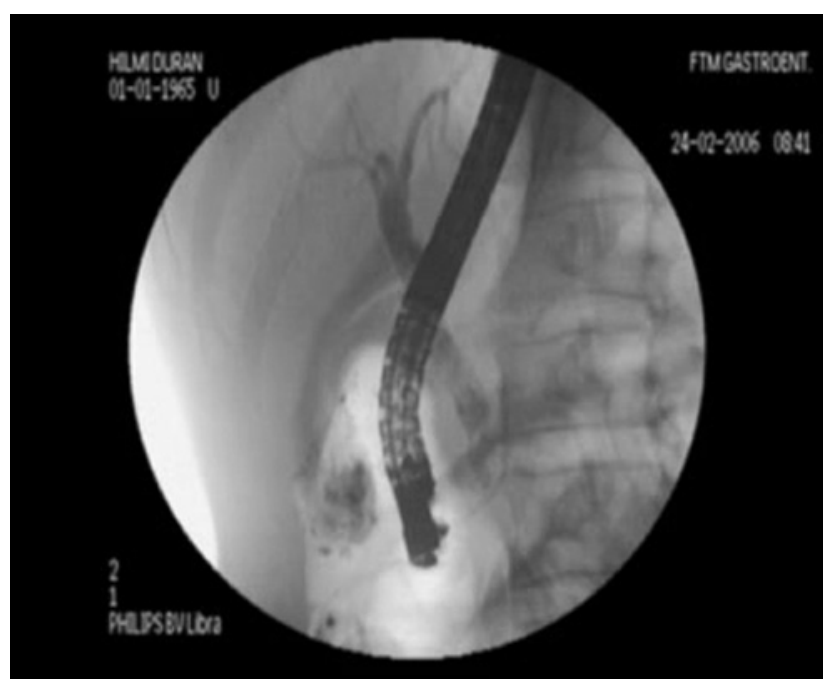

Fig. 1: Endoscopic retrograde cholangiography images: The patient's common bile ducts were slighly dilated, and a radiolucent, irreguler filling defect in common bile duct. 
normal. After the extraction of the balloon, the clot was removed and there was a gush of bleeding. The procedure was ended, and urgent laparotomy was performed. The CBD exploration was conducted during the operation. An ulcer in the median part of the CBD and massive arterial bleeding from this part was observed. It was seen that there was a dead FH parasite on the same ulcer floor. It was established that the focus of bleeding was not associated with the previous sphincterotomy. Choledochotomy, partial choledochus resection, hepaticojejunostomy, and cholecystectomy were conducted. The patient was discharged on the $14^{\text {th }}$ postoperative day.

\section{Discussion}

The infection has two clinical phases: the acute phase which covers the hepatic invasion of the parasite, and the chronic phase when the parasite is found in biliary tracts. In its acute phase it infects people upon eating contaminated water cress. The FH helminth arrives from the duodenum first to the peritoneal cavity, and then to the liver capsule. The helminth that perforates the liver capsule gets into biliary tracts. Another route by which it reaches biliary tracts is blood and lymph vessels. After it arrives at the biliary tracts, the helminth develops and becomes an adult in 3 months $(6,14)$. Extended fever, pain in the upper right quadrant, hepatomegaly and eosinophilia are observed in the acute phase, and may easily go unnoticed. Most of the symptoms depend on sensitivity to secretions (attacks of urticaria, migraine episodes, quincke edema). These signs disappear in the chronic phase, when cholestasis and cholangitis signs are observed due to the presence of the parasite in the biliary tracts $(3,15)$. Severe complications like hemorrhage are rarely seen. The literature includes a few case reports $(12,17)$.

In one case, ulcer formation in and hemorrhage from the CBD were observed (1). In this case, ulceration in and hemorrhage from the CBD medina-distal area were seen. The ulcer formation is attributed to the parasite's entering the papilla of Vater in the duodenum and perforating the choledochus there. In our case, the presence of epigastric pain for one month in the clinical course and finding mature, but dead parasites by ERCP indicate that the disease was in the chronic phase. Ulcer formation of the parasite in the $\mathrm{CBD}$ is rare but possible.
Although a definitive diagnosis of the parasite is given by establishing parasite eggs in the feces or duodenal aspirate, this method's chances of success are slim due to the fact that the parasite produces few eggs. Therefore, serological tests are used in the early period (4). Diagnosis is frequently made by chance during surgery; rarely is the diagnosis given during ERCP upon seeing the parasite itself $(5,7)$.

In conclusion, when searching for the causes of hepatobiliary diseases, Fasciola hepatica should be considered. Fasciola hepatica should also be borne in mind among the causes of hemobilia.

\section{References}

1. Acuna-Soto R, Braun-Roth G. Bleeding ulcer in the common bile duct due to Fasciola hepatica. Am J Gastroenterol. 1987;82:560-2.

2. Aksoy DY, Kerimoglu U, Oto A, et al. Fasciola hepatica infection: Clinical and computerized tomographic findings of ten patients. Turk J Gastroenterol. 2006; $17: 40-45$.

3. Almendras-Jaramillo M, Rivera-Medina J, Seijas-Mogrovejo J, Almendras-Jaramillo K. Hepatic fascioliasis in children:uncommon clinical manifestations Arq Gastroenterol. 1997;34:241-7 (Abstract).

4. Carnevale $\mathrm{S}$, Rodriguez $\mathrm{M}$ al. Immunodiagnosis of human fascioliasis by an enzyme-linked immunosorbent assay (ELISA) and a micro-ELISA. Clin Diagn Lab Immunol. 2001;8:174-7.

5. Dobrucali A, Yigitbasi R, Erzin Y, Sunamak O, Polat E, Yakar H. Fasciola hepatica infestation as a very rare cause of extrahepatic cholestasis. World J Gastroenterol. 2004 ; 10:3076-7.

6. El-Shazly AM, Soliman M, Gabr A, et al. Clinico-epidemiological study of human fascioliasis in an endemic focus in Dakahlia Governorate, Egypt. J Egypt Soc Parasitol. 2001;31:725-36.

7. Gulsen MT, Savas MC, Koruk M, Kadayifci A, Demirci F. Fascioliasis: a report of five cases presenting with common bile duct obstruction. Neth J Med. 2006:64:17-9

8. Harinasuta T, Bunnag D. Liver, lung and intestinal trematodiasis. In: Warren KS, Mahmoud AF, eds. Tropical and Geographical Diseases. 2nd ed. New York: McGraw-Hill, 1990;473-89.

9. Haseeb AN, A review on fascioliasis in Egypt. J Egypt Soc Parasitol. 2002;32: 317-54.

10. Haseeb AN, El-Shazly AM, Arafa MA, Morsy AT. Clinical, laboratory and ultrasonography features of proven human fascioliasis. J Egypt Soc Parasitol. 2003; 33:397-412

11. Kaplan M, Kuk S, Kalkan A, Demirdag K, Ozdarendeli A. Fasciola hepatica seroprevalence in the Elazig region. Mikrobiyol Bul. 2002;36:337-42.

12. Legua P Dr. Parasitary infections of the liver. Rev Gastroenterol Peru. 1997;17 1: 115-127 (Abstract)

13. Mas-Coma S. Epidemiology of fascioliasis in human endemic areas. J Helminthol. 2005;79:207-16.

14. Mas-Coma MS, Esteban JG, Bargues MD. Epidemiology of human fascioliasis: a reviev and proposed new classification. Bull World Health Organ. 1999;77(4):340-6.

15. Saba R, Korkmaz M, Inan D, et al. Human fascioliasis Clin Microbiol Infect. 2004;10:385-7.

16. Veerappan A, Siegel JH, Podany J, Prudente R, Gelb A. Fasciola hepatica pancreatitis: endoscopic extraction of live parasites. Gastrointest Endosc. 1991;37:473-5.

17. Wong RK, Peura DA, Mutter ML, Heit HA, Birns MT, Johnson LF. Hemobilia and liver flukes in a patient from Thailand. Gastroenterology. 1985;88:1958-63.

\section{Corresponding author:}

Dr. I. Halil Bahcecioglu, Firat Üniversitesi, Tip Fakültesi Gastroenteroloji BD,

Elazig, Turkey, e-mail: ihbahcecioglu@yahoo.com 